\title{
Oral impacts on daily performances in white-collar port workers in Nellore, India - a cross-sectional study
}

\author{
Mandava Soundarya Chowdary, Kudlur Maheswarappa Sudhir, Vuyurru Chandrasekhara Reddy, \\ Rathikota Veera Venkata Sathya sai Krishna Kumar, Gomasani Srinivasulu
}

Department of Public Health Dentistry, Narayana Dental College and Hospital, Chinthareddypalem, Nellore, AP, India

\begin{abstract}
Background: Oral diseases not only cause pain, but severely impair large number of individuals and can affect various aspects of life, including oral functions, appearance and interpersonal relationships. The aim of the study was to assess the interrelationship between oral impact on daily performance (OIDP) scores, socio-demographic characteristics, dental caries experience and periodontal status.

Materials and methods: A cross-sectional descriptive epidemiological study was conducted on a sample of 250 white-collar port workers who were willing to participate. OIDP was assessed using pre-validated questionnaire. Oral health status was assessed using modified World Health Organisation (1997) Proforma. Test of association was conducted between the OIDP score, socio-demographic variables, and periodontal status; loss of attachment was determined by using chi-square statistics and Mann-Whitney test. Logistic regression was performed to identify significant predictors of OIDP scores by inputting clinical oral examination variables into the equation, stepwise.

Results: A total of 250 white-collar workers in the port participated in the study with mean age of $34.67 \pm$ \pm 6.36 . Among them, 219 were males and 31 were females. The OIDP items most commonly affected by oral health status were eating and enjoying food (48.4\%), cleaning teeth (48\%), sleeping and relaxing (44.4\%).There was statistically significant relationship between missing teeth in the decayed missing filled teeth component and OIDP score $(p<0.001)$. The participants with caries have a greater odd (2.11) of having OIDP score $\geq 1$ than those without caries. The participants with missing teeth have a greater odd (3.60) of having OIDP score $\geq 1$. The participants in the age group of 31-40 years had a greater odd (2.80) of having OIDP score $\geq 1$.

Conclusions: Oral health had an impact on the quality of life of white-collar workers in the port. Physical functions of teeth like eating and cleaning of teeth, sleeping and relaxing were more affected.
\end{abstract}

(Int Marit Health 2016; 67, 4: 205-213)

Key words: oral impact on daily performance, port workers, oral health status

\section{INTRODUCTION}

Health is a fundamental human right. Being healthy, an individual can lead a happy life, increase the productivity and enjoy the quality of life (QoL). Oral health is important to maintain good general health, which in turn influences the QoL, growth, looks, speech, mastication of food, socialisation, as well as the sense of social well-being. Oral diseases such as dental caries and periodontal disease are highly prevalent, and their consequences are not only physical but also economic, social and psychological. Oral diseases not only cause pain, but may also lead to social embarrassment and trigger processes of suffering, making the whole body suffer [1]. They severely impair large number of individuals and can affect various aspects of life, including oral functions, appearance and interpersonal relationships. Like health related QoL, oral health-related QoL is a multi-

Dr. Mandava Soundarya Chowdary, Department of Public Health Dentistry, Narayana Dental College and Hospital, Chinthareddypalem, Nellore, AP, India,

e-mail: manju7chowdary@gmail.com 
dimensional concept that incorporates survival, illness and impairment, social, psychological and physical function and disability, oral health perceptions, opportunity, as well as interactions between the aforementioned domains [2]. Oral health-related QoL is a relatively new but rapidly growing phenomenon that has emerged over the past two decades [3]. Among all the oral health-related QoL instruments, Oral impacts on daily performance (OIDP) is a scale that assesses the impact of oral diseases on individuals' daily life. OIDP instrument is advantageous for use in population surveys. It is not only user-friendly but also it measures behaviour state rather than feeling state. It is based on an explicit conceptual framework, the World Health Organisation's International Classification of Impairments, Disabilities and Handicaps (ICIDH) [4], that has been amended for dentistry by Locker [4]. The OIDP provides a final score that incorporates the measurements of both the frequency and the severity of major oral impacts in the last 6 months. Krishnapatnam port is one of the 14 notified non-major deep water ports on the East coast of India located in Nellore, Andhra Pradesh. It performs different activities including processing of coal and coke, food and agro, fertilizers, carbon black, LPG/LNG, POL products, petrochemical products, specialty chemicals and edible oil, transport of automobiles, amenities, utilities etc. Therefore, a large number of employees, especially engineers are necessary for proper functioning of the activities in the port. The employees will be given particular deadlines and responsibilities for handling the equipment and transportation. Reaching these goals is important for proper functioning of the port. This study was undertaken to assess the oral health of the white-collar port workers and whether oral health has any effect on the daily activities of port workers.

The aim of the study was to assess the oral impacts on daily performances among white-collar port workers in Nellore, Andhra Pradesh, India (a cross-sectional study). Objectives included:

- to assess the socio-demographic details of white-collar workers in port;

- to assess the oral health-related quality of life with the help of the OIDP questionnaire;

- to assess the dental caries and periodontal condition of the employees;

- to analyse the interrelationship between OIDP scores, socio-demographic characteristics, dental caries experience and periodontal status.

\section{MATERIALS AND METHODS}

\section{STUDY DESIGN}

A cross-sectional descriptive epidemiological study was conducted to assess the oral impacts on daily perfor- mances among white-collar port workers in Nellore, Andhra Pradesh, India.

\section{SETTING AND POPULATION}

The study was conducted among port employees working in Krishnapatnam port, Nellore, Andhra Pradesh. Krishnapatnam port is one of the 14 notified non-major deep water ports on the East coast of India. There are 40 departments in the port performing different activities. The white-collar workers working in different departments who were willing to participate and gave informed consent were included in the study.

\section{SOURCE OF DATA}

The source of data is primary in nature for which a survey consisting of questionnaire and clinical examination was conducted.

\section{SAMPLING}

The participants who were available at the time of the study, willing to participate and who gave informed consent were included in the study.

\section{ETHICAL CLEARANCE}

Ethical clearance was obtained from institutional review board of Narayana Dental College and Hospital. Permissions from the respective head of Krishnapatnam port was taken prior to the start of the study.

\section{Inclusion criteria}

White-collar port workers who were willing to participate in the study and who agreed for oral clinical examination and who gave an informed consent were included in the study.

\section{VARIABLES}

The data was collected using interview and clinical examination. A questionnaire consisting of two parts was used for data collection. The first part consisted of socio-demographic details and the OIDP [5] questionnaire; second part consisted of assessment of dental caries with the help of dentition status and periodontal status using community periodontal index (CPI) and loss of attachment (LOA) (see Appendix).

\section{STUDY DURATION}

The study was conducted from $4^{\text {th }}$ January 2016 to $4^{\text {th }}$ February 2016.

\section{CALIBRATION OF EXAMINERS AND INSTRUMENT}

The investigator was trained and calibrated for data recording in the Department of Public Health Dentistry, Narayana Dental College and Hospital before conducting 
Table 1. Prevalence of oral impacts on daily performances among the port workers

\begin{tabular}{lllll}
\hline & Impact & Mean frequency & Mean severity & Mean total \\
\hline Eating & $121(48.4 \%)$ & $0.61(0.71)$ & $0.66(0.76)$ & $0.8(1.00)$ \\
Speaking & $20(8 \%)$ & $0.11(0.42)$ & $0.09(0.34)$ & $0.08(0.37)$ \\
Cleaning & $120(48 \%)$ & $0.62(0.74)$ & $0.62(0.71)$ & $0.8(1.09)$ \\
Sleep & $111(44.4 \%)$ & $0.58(0.74)$ & $0.55(0.70)$ & $0.73(1.05)$ \\
Smiling & $11(4.4 \%)$ & $0.07(0.37)$ & $0.06(0.26)$ & $0.07(0.39)$ \\
Emotion & $24(9.6 \%)$ & $0.13(0.42)$ & $0.12(0.41)$ & $0.17(0.63)$ \\
Work & $18(7.2 \%)$ & $0.09(0.38)$ & $0.07(0.29)$ & $0.09(0.41)$ \\
Contact & $14(5.6 \%)$ & $0.07(0.29)$ & $0.05(0.23)$ & $0.05(0.26)$
\end{tabular}

the study. Training was carried on for the examiner until she produced consistent observations. Twenty five subjects were examined and re-examined on successive days. Intra-examiner reproducibility was evaluated through per cent agreement and Cohen's kappa Statistics pertaining to CPI, LOA and decayed missing filled teeth (DMFT) indices. The OIDP questionnaire was pre-validated; Cronbach alpha of the scale (internal consistency among items of questions) was 0.65 . The standard item alpha, in which all items variances were standardised, was 0.67 [5]. The scale used was in the range: $\{0\}$ "never affected", $\{1\}$ "less than once a month", $\{2\}$ "once or twice a month", $\{3\}$ "once or twice a week", $\{4\}$ "3 times a week", $\{5\}$ "every or nearly every day". Finally, the OIDP SC frequency scores were dichotomised, yielding the categories [0] "no daily performance affected" and [1] "at least one daily performance affected".

\section{STATISTICAL ANALYSIS}

Statistical analysis was performed using SPSS software programme. Test of association was conducted between the OIDP score and socio-demographic variables using $\chi^{2}$ statistics. Association between OIDP score and periodontal status, loss of attachment was determined by using Mann-Whitney test. Logistic regression was performed to identify significant predictors of OIDP scores by inputting clinical oral examination variables into the equation, stepwise.

\section{RESULTS}

A total of 250 white-collar workers in the port with mean age of $34.67 \pm 6.36$ participated in the study. Among them, 219 were males and 31 were females.

The OIDP items most commonly affected by oral health status were eating and enjoying food (48.4\%), cleaning teeth (48\%), sleeping and relaxing (44.4\%). The least commonly affected were speaking and pronouncing words clearly (8\%), carrying out daily work (7.2\%), maintaining usual emotional status (9.6\%), smiling and showing teeth (4.4\%) and enjoying social contact with people (5.6\%) (Table 1).

A total of 165 white-collar workers reported some impact of oral health on their daily performance (i.e. OIDP score $>0$ ). The participants aged 31-40 years showed OIDP score $>0$ which was statistically significant. There were no statistically significant differences between OIDP score and gender, education, profession, income and socio-economic status (Table 2).

Table 3 shows the relationship between DMFT scores of the participants and OIDP scores. There was statistically significant relationship between missing teeth in the DMFT component and OIDP score $(p<0.001)$. Subjects with missing teeth had a higher impact on their daily performance.

The participants with CPI scores of 0, 1 and 2 had an impact on their daily performance with OIDP scores $\geq 1$. There was no significant association between OIDP score of participants and their periodontal condition (Table 4).

The participants with LOA scores of 0, 1 and 2 had an impact on their daily performance with OIDP scores $\geq 1$. There was no significant association between OIDP score of participants and their loss of attachment (Table 5).

Majority of the participants (96.4\%) showed periodontitis and only $2 \%$ of them were without periodontal disease. $72.4 \%$ of the participants had loss of attachment and $27.6 \%$ were healthy. $62.8 \%$ of the participants had dental caries and $32.4 \%$ had their teeth missing (Table 6).

The participants with caries had a greater odd of having OIDP score $\geq 1$ than those without caries (odds ratio [OR] $2.11,95 \%$ confidence interval $[\mathrm{Cl}] 1.16-3.79, \mathrm{p}=0.01$ ). The participants with missing teeth have a greater odd of having OIDP score $\geq 1$ (OR 3.60, 95\% Cl 1.83-7.07, $p=0.001$ ). The DMFT status was not a significant predictor of OIDP score. Compared to the reference group the participants with a age group of 31-40 years had a greater odd of having OIDP score $\geq 1$ (OR 2.08, 95\% Cl 1.12-3.85, $\mathrm{p}=0.02$ ) (Table 7). 
Table 2. Relationship between oral impact on daily performance (OIDP) score and socio-demographic characteristics

\begin{tabular}{|c|c|c|c|c|c|c|}
\hline & & \multicolumn{2}{|l|}{ OIDP } & \multirow[t]{2}{*}{ Total } & \multicolumn{2}{|c|}{ Chi square test } \\
\hline & & 0 & 1 & & Value & $\mathbf{P}$ \\
\hline \multirow[t]{3}{*}{ Age } & $20-30$ years & 38 (43.2\%) & $50(56.8 \%)$ & 88 (35.2\%) & 6.29 & $0.04 *$ \\
\hline & $31-40$ years & 31 (26.5\%) & 86 (73.5\%) & 117 (46.8\%) & & \\
\hline & $41-50$ years & $16(35.6 \%)$ & $29(64.4 \%)$ & 45 (18\%) & & \\
\hline \multirow[t]{2}{*}{ Sex } & Male & 72 (32.9\%) & 147 (67.1\%) & 219 (87.6\%) & 0.99 & 0.31 (NS) \\
\hline & Female & $13(41.9 \%)$ & $18(58.1 \%)$ & 31 (12.4\%) & & \\
\hline \multirow[t]{2}{*}{ Education } & 0 and 1 & $10(45.5 \%)$ & $12(54.5 \%)$ & $22(8.8 \%)$ & 1.41 & 0.23 (NS) \\
\hline & 2 and 3 & 75 (32.9\%) & 153 (67.1\%) & 228 (91.2\%) & & \\
\hline \multirow[t]{2}{*}{ Occupation } & 1 & 75 (32.8\%) & $154(67.2 \%)$ & 229 (91.6\%) & 1.89 & 0.16 (NS) \\
\hline & 2 and 3 & $10(47.6 \%)$ & 11 (52.4\%) & $21(8.4 \%)$ & & \\
\hline \multirow[t]{2}{*}{ Income } & 1 & 38 (35.2\%) & $70(64.8 \%)$ & $108(43.2 \%)$ & 0.11 & 0.73 (NS) \\
\hline & $2,3,4$ & 47 (33.1\%) & 95 (66.9\%) & $142(56.8 \%)$ & & \\
\hline \multirow{2}{*}{$\begin{array}{l}\text { Socio-economic } \\
\text { status }\end{array}$} & 0 and 1 & 78 (32.9\%) & 159 (67.1\%) & 237 (94.8\%) & 2.40 & 0.12 (NS) \\
\hline & 2 and 3 & 7 (53.8\%) & $6(46.2 \%)$ & 13 (5.2\%) & & \\
\hline
\end{tabular}

${ }^{*} p<0.05$ - statistically significant; $p>0.05$ : NS - non-significant

Table 3. Relationship between oral impact on daily performance (OIDP) score of participants and decayed missing filled teeth (DMFT) index findings

\begin{tabular}{|c|c|c|c|c|c|c|}
\hline & & \multicolumn{2}{|l|}{ OIDP } & \multirow[t]{2}{*}{ Total } & \multicolumn{2}{|c|}{ Chi square test } \\
\hline & & 0 & 1 & & Value & $\mathbf{P}$ \\
\hline \multirow[t]{2}{*}{ D } & 0 & 37 (39.8\%) & $56(60.2 \%)$ & 93 (37.2\%) & 2.20 & 0.13 (NS) \\
\hline & 1 & 48 (30.6\%) & 109 (69.4\%) & 157 (62.8\%) & & \\
\hline \multirow[t]{2}{*}{ M } & 0 & 70 (41.4\%) & 99 (58.6\%) & $169(67.6 \%)$ & 12.79 & $<0.001^{*}$ \\
\hline & 1 & 15 (18.5\%) & $66(81.5 \%)$ & 81 (32.4\%) & & \\
\hline \multirow[t]{2}{*}{$\mathrm{F}$} & 0 & 29 (31.2\%) & 64 (68.8\%) & 93 (37.2\%) & 0.52 & 0.46 (NS) \\
\hline & 1 & 56 (35.7\%) & $101(64.3 \%)$ & 157 (62.8\%) & & \\
\hline \multirow[t]{2}{*}{ DMFT } & 0 & 34 (39.1\%) & $53(60.9 \%)$ & 87 (34.8\%) & 1.53 & 0.21 (NS) \\
\hline & 1 & $51(31.3 \%)$ & $112(68.7 \%)$ & $163(65.2 \%)$ & & \\
\hline
\end{tabular}

${ }^{*} p<0.05$ - statistically significant; $p>0.05$ : NS - non-significant

Table 4. Relationship between oral impact on daily performance (OIDP) score of participants and periodontal status

\begin{tabular}{|c|c|c|c|c|c|c|}
\hline & \multicolumn{2}{|l|}{0 Impact } & \multicolumn{2}{|l|}{1 and more } & \multicolumn{2}{|c|}{ Mann Whitney U test } \\
\hline & Mean (SD) & Median (Q1-Q3) & Mean (SD) & Median (Q1-Q3) & U statistic & $\mathbf{P}$ \\
\hline CPI 0 & $3.87(0.84)$ & $4(3-4)$ & $3.92(0.69)$ & $4(3.5-4)$ & 6610.50 & 0.41 (NS) \\
\hline CPI 1 & $1.77(0.74)$ & $2(1-2)$ & $1.75(0.68)$ & $2(1-2)$ & 6790.00 & 0.65 (NS) \\
\hline CPI 2 & $0.32(0.56)$ & $0(0-1)$ & $0.31(0.53)$ & $0(0-1)$ & 6967.50 & 0.92 (NS) \\
\hline CPI 3 & $0.01(0.10)$ & $0(0-0)$ & $0(0)$ & $0(0-0)$ & 6930.00 & 0.16 (NS) \\
\hline CPI 4 & $0.01(0.10)$ & $0(0-0)$ & $0(0)$ & $0(0-0)$ & 6930.00 & 0.16 (NS) \\
\hline
\end{tabular}

${ }^{*} p<0.05$ - statistically significant; $p>0.05$ : NS - non-significant; SD - standard deviation; $\mathrm{CPI}-$ community periodontal index 


\section{DISCUSSION}

Quality of life has become a major topic of interest among both academics and the general public with regard to planning and policy for well-being. Therefore, in the same way that research studies are diversified according to the proposed objective, the concept of QoL also takes on differ-

Table 5. Relationship between oral impact on daily performance (OIDP) score of participants and loss of attachment

\begin{tabular}{|c|c|c|c|c|c|c|}
\hline & \multicolumn{2}{|l|}{0 Impact } & \multicolumn{2}{|l|}{1 and more } & \multicolumn{2}{|c|}{ Mann Whitney U test } \\
\hline & Mean (SD) & Median (Q1-Q3) & Mean (SD) & Median (Q1-Q3) & U statistic & $\mathbf{P}$ \\
\hline LOA 0 & $5.05(0.74)$ & $5(5-6)$ & $4.98(0.77)$ & $5(4-6)$ & 6641.50 & 0.45 (NS) \\
\hline LOA 1 & $0.94(0.74)$ & $1(0-1)$ & $1.01(0.77)$ & $1(0-2)$ & 6641.50 & 0.45 (NS) \\
\hline LOA 2 & 0 & 0 & 0 & 0 & - & - \\
\hline LOA 3 & 0 & 0 & 0 & 0 & - & - \\
\hline LOA 4 & 0 & 0 & 0 & 0 & - & - \\
\hline
\end{tabular}

Table 6. Prevalence of dental caries and periodontal diseases among the participants

\begin{tabular}{lll}
\hline Scores & Present & Absent \\
\hline CPI 0 (all sextant healthy) & $5(2 \%)$ & $245(98 \%)$ \\
CPI 1 & $241(96.4 \%)$ & $9(3.6 \%)$ \\
CPI 2 & $70(28 \%)$ & $180(72 \%)$ \\
CPI 3 & $1(0.4 \%)$ & $249(99.6 \%)$ \\
CPI 4 & $1(0.4 \%)$ & $249(99.6 \%)$ \\
LOA 0 (all sextant healthy) & $69(27.6 \%)$ & $181(72.4 \%)$ \\
LOA1 & $181(72.4 \%)$ & $69(27.6 \%)$ \\
LOA 2 & 0 & $250(100 \%)$ \\
LOA 3 & 0 & $250(100 \%)$ \\
LOA 4 & 0 & $250(100 \%)$ \\
Decayed & $157(62.8 \%)$ & $93(37.2 \%)$ \\
Missing & $81(32.4 \%)$ & $169(67.6 \%)$ \\
Filled & $157(62.8 \%)$ & $93(37.2 \%)$ \\
DMFT combined & $163(65.2 \%)$ & $87(34.8 \%)$
\end{tabular}

$\mathrm{CPI}$ - community periodontal index; LOA - loss of attachment; DMFT - decayed missing filled teeth ent definitions as a result of its multidisciplinary use. In this investigation, the concept of QoL was considered as the individual's perception of his/her own life as in the sense that perceptions of life are permeated by the socio-economic and psychological conditions particular to each individual. An important attribute of any psychometric instrument is its ability to measure what it intends to measure in a meaningful and useful way [6-8]. Cross-cultural adaptation of socio-dental indicators requires rigorous translation and validation to make the adopted instrument culturally relevant for the local population. The OIDP scale assesses impacts of oral health conditions that affect daily activities of an individual and is commonly used as oral health-related QoL indicator. Also it is important self-reported information of patients about changing their oral conditions and affecting daily life for the clinicians. Previous applications of the OIDP scale to various populations have yielded internal consistency values ranging from 0.67 to 0.85 [9-11]. The participants of the present study were familiar with English as a second language, thus a rigorous translation and back translation was deemed unnecessary. A total of 250 white-collar workers in the port with mean age of $34.67 \pm 6.36$ participated

Table 7. Logistic regression analysis of relationship between oral impacts on daily performance score and oral examination findings

\begin{tabular}{|c|c|c|c|c|c|c|}
\hline & \multirow[t]{2}{*}{ B } & \multirow[t]{2}{*}{ SE } & \multirow[t]{2}{*}{$\mathbf{P}$} & \multirow[t]{2}{*}{ Odds ratio } & \multicolumn{2}{|c|}{ 95\% $\mathrm{Cl}$ for odds ratio } \\
\hline & & & & & Lower & Upper \\
\hline Decayed & 0.74 & 0.30 & $0.01 *$ & 2.11 & 1.16 & 3.79 \\
\hline Missing & 1.28 & 0.34 & $<0.001^{*}$ & 3.60 & 1.83 & 7.07 \\
\hline Age $20-30$ years (reference) & & & 0.06 (NS) & & & \\
\hline Age $31-40$ years & 0.73 & 0.31 & $0.02 *$ & 2.08 & 1.12 & 3.85 \\
\hline Age $41-51$ years & 0.35 & 0.39 & 0.36 (NS) & 1.42 & 0.65 & 3.07 \\
\hline Constant & -0.54 & 0.32 & 0.09 (NS) & 0.58 & & \\
\hline
\end{tabular}

Cox and snell $R^{2}=0.09$, Nagelkerke $R^{2}=0.13$; Model Chi square $(3)=24.75 ; p<0.001 ;{ }^{\star} p<0.05$ - statistically significant; $p>0.05$ : NS - non-significant; $\mathrm{Cl}$ - confidence interval; SE - standard error 
in the study. Dorri et al. [12] examined the validity and reliability of the OIDP inventory among Iranian 20-50-yearold employees in Mashhad [12]. In the present study, all participants explained that oral and dental problems had affected at least one of their daily activities. In other words, the prevalence of OIDP was very high. A total of $66 \%$ of the participants reported experiencing an oral impact that affected their daily life in the past 6 months. The total impact prevalence rate was comparable with the Tanzanian study, using similar methodology and an English version questionnaire [9]. It was also below $70 \%$ observed in Western population with high dental disease levels and in a low oral disease Thai population [10]. Different values have been reported for the prevalence of OIDP by Kida et al. [13] (51.2\% in urban and $61.2 \%$ in rural areas), Dorri et al. [12] (64.9\%), Srisilapanan and Sheiham [14] (52.8\%), Jung et al. [15] (62.9\%). The 8 impact prevalence rates ranged from $4.4 \%$ to $48.4 \%$. The OIDP items most commonly affected by oral health status were eating and enjoying food (48.4\%), cleaning teeth (48\%), sleeping and relaxing (44.4\%). Consistent with the results reported in previous OIDP surveys, difficulty with eating and enjoying food and with cleaning teeth were the impacts most frequently reported [16-20]. Eating and cleaning teeth are more frequently impacted upon than other activities because of the importance of food and nutrition to humans; hence; high consideration is attached to the feeding process. Impairment of this activity or cleaning the teeth before or after meals is also considered very important to individuals. The least commonly affected were speaking and pronouncing words clearly (8\%), carrying out daily work (7.2\%), maintaining usual emotional status (9.6\%), smiling and showing teeth (4.4\%) and enjoying social contact with people (5.6\%). These findings were similar to the reports of study conducted by Nurelhuda et al. [21] and Mbawalla et al. [22] who reported speaking as the least frequently affected activity. Smiling was also least frequently affected in a study done by Kakoei et al. [23]. In our study, the psychological and social impacts were less frequently reported. Maintaining usual emotional status and enjoying social contact were rarely impacted upon by the oral health status of the participants. Similar results were published by others [17, 24].

Individual expectations, experiences and preferences influence subjective oral health evaluation and these factors may change with age, education levels and absence of natural teeth. Oral health-related QoL is affected by several factors such as age, gender, socio-economic status and tooth loss [25]. The relationships between socio-demographic factors, dental status and oral health related QoL were investigated in previous studies [24, 26]. Age in the present study was significantly associated with mean OIDP score $(p=0.04)$. OIDP was tested in various adult populations with varying age groups; for example 35-44-year-old adults in Thai population; 44 years in Norway, 20-50-year-olds in Persia; older groups of 63, 65 and 69 years in Tanzania, Japan and Korea; younger populations of 16 and 10-11 years in Uganda and Britain, respectively [27]. In the present study there was no significant association between sex, education, profession and income. These findings were similar to a study done by Kakoei et al. [23]. A study done by Pereira et al. [28] did not find a statistically significant association between daily impacts and education level of the elderly, whereas the study by Gomes et al. [29] reported no association of impacts with the income of adults.

The study also found that participants with dental caries were more likely to report their oral condition as having impacted on their daily performances compared to those without dental caries. The pain that accompanies dental caries invariably draws the attention of the individual, leading therefore to significant influences on their daily performances. These findings were similar to the studies done my Lawal et al. [30], Adekoya-Sofowora et al. [31]. Missing teeth showed a significant association with OIDP scores. This was similar to a study done by Ilha et al. [32]. A study of a Ugandan population, students with missing teeth were 3.4 times more likely to report difficulties with sleeping and relaxing than those with no missing teeth [20]. The reason may be that tooth loss, if teeth are not replaced, can have serious consequences, ranging from subjective feelings, such as shame, embarrassment, incompleteness and resignation. Our study revealed that periodontal disease, though prevalent amongst the participants, had no significant impact on their daily activities. The chronicity of the disease may account for this. It is probable that they perceived no harm with a condition when it is not associated with pain. Periodontal disease in general is notorious for being painless unless complicated. These findings are similar to a study done by Lawal et al. [30]. The logistic regression analysis in the present study showed that the participants with dental caries, missing teeth and age as significant predictors of OIDP scores and has at least one impact on their daily life.

\section{LIMITATIONS OF THE STUDY}

The sampling was convenient sampling and only port workers from a single port were taken excluding other ports in Andhra Pradesh. It is not known whether the results can be generalised to all white-collar port workers.

\section{CONCLUSIONS}

Oral health had an impact on the QoL of white-collar workers in the port. Physical functions of teeth like eating and cleaning of teeth, sleeping and relaxing were more affected. 


\section{RECOMMENDATIONS}

There is a need to promote oral health among white-collar port workers emphasizing the importance of prevention of common oral diseases that do not significantly impact their daily activities in order to avoid the complications associated with oral diseases. Effective oral health education and promotion workshops should be organised for port workers. The workshops should be aimed at changing the perception that oral health is disparate to general health, and emphasis should be placed on the importance of oral health and its relationship with general health.

\section{REFERENCES}

1. Sheiham A. Oral health, general health and quality of life. Bull World Health Organ 2005; 83: 644.

2. Gift HC, Atchison KA. Oral health, health, and health-related quality of life. Med Care 1995; 33: NS57-NS77.

3. Healthy People 2010. Washington DC, United States Department of Health and Human Services, Government Printing Office; 2000, 8.

4. Locker D. Measuring oral health: a conceptual frame work. Community Dent Health 1988; 5: 3-18.

5. Adulyanon S, Sheiham A. Oral impacts on daily performances. In: Measuring oral health and quality of life. In: Slade GD (ed.) University of North Carolinas, Chapel Hill 1997.

6. Nachmias D, Nachmaias CF. Research methods in the social sciences. 6th Ed. Worth Publishers, New York 1999.

7. Bryman A. Social research methods. $2^{\text {nd }}$ Ed. Oxford University Press, Oxford 2004

8. Brondani M, MacEntee MI. Dental Psychometric and a Re(de)fined Model for Oral Health in Old Age. Saarbrbucken, Germany 2008.

9. Masalu JR, Astrom AN. Social and behavioral correlates of oral quality of life studied among university students in Tanzania. Acta Odontol Scand 2002; 60: 353-359.

10. Adulyanon S, Vourapukjaru J, Sheiham A. Oral impacts affecting daily performance in a low dental disease Thai population. Community Dent Oral Epidemiol 1996; 24: 385-389.

11. Tsakos G, Marcenes W, Sheiham A. Evaluation of a modified version of the index of oral impacts on Daily performances (OIDP) in elderly populations in two European countries. Gerodontology 2001; 18: 121-130.

12. Dorri M, Sheiham A, Tsakos G. Validation of a Persian version of the OIDP index. BMC Oral Health 2007; 7: 2.

13. Kida IA, Astrom AN, Strand GV, Masalu JR, Tsakos G. Psychometric properties and the prevalence, intensity and causes of oral impacts on daily performance (OIDP) in a population of older Tanzanians. Health Qual Life Outcomes 2006; 4: 56.

14. Srisilapanan $P$, Sheiham $A$. The prevalence of dental impacts on daily performances in older people in Northern Thailand. Gerodontology 2001; 18: 102-108.

15. Jung SH, Ryu JI, Tsakos G, Sheiham A. A Korean version of the Oral Impacts on Daily Performances (OIDP) scale in elderly populations: validity, reliability and prevalence. Health Qual Life Outcomes 2008; 6: 17.
16. Cortes MIS, Marcenes W, Sheiham A. Impact of traumatic injuries to the permanent teeth on the oral health related quality of life in 12-14 year old children. Community Dent Oral Epidemiol 2002, 30: 193-198.

17. Masalu J, Astrom AN. Applicability of an abbreviated version of the oral impacts on daily performances (OIDP) scale for use among Tanzanian students. Community Dent Oral Epidemiol 2003, 31: 7-14.

18. Adulyanon S, Vourapukjaru J, Sheiham A. Oral impacts affecting daily performance in a low dental disease Thai population. Community Dent Oral Epidemiol 1996; 24: 385-389.

19. Tsakos G, Marcenes W, Sheiham A. Cross-cultural differences in oral impacts on daily performance between Greek and British older adults. Community Dent Health 2001; 18: 209-213.

20. Astrom AN, Okullo I. Validity and reliability of the Oral Impacts on Daily Performance (OIDP) frequency scale: a cross-sectional study of adolescents in Uganda. BMC Oral Health 2003, 3: 5.

21. Nurelhuda NM, Ahmed MF, Trovik TA, Astrom AN. Evaluation of oral health-related quality of life among Sudanese schoolchildren using Child-OIDP inventory. Health Qual Life Outcomes 2010; 8: 152.

22. Mbawalla HS, Masalu JR, Astrom AN. Socio-demographic and behavioural correlates of oral hygiene status and oral health related quality of life, the Limpopo-Arusha school health project (LASH): a cross-sectional study. BMC Pediatr 2010; 10: 87.

23. Kakoei S, Shokoohi M, Barghi H. Oral impact on daily performance in Iranian adults. J Oral Health Oral Epidemiol 2013; 2: 6-12.

24. Astrom AN, Haugejorden O, Skaret E, Trovik TA, Klock KS. Oral Impacts on Daily Performance in Norwegian adults: the influence of age, number of missing teeth, and socio-demographic factors. Eur J Oral Sci 2006; 114: 115-121.

25. John MT, Koepsell TD, Hujoel P, Miglioretti DL, Leresche L, Micheelis W. Demographic factors, denture status and oral health related quality of life. Community Dent Oral Epidemiol 2004; 32: 125-132.

26. Steele JG, Sanders AE, Slade GD, Allen PF, LahtiS, Nuttall N, SpencerAJ. How do age and tooth loss affect oral health impacts and quality of life? A study comparing two national samples. Community Dent Oral Epidemiol 2004; 32: 107-114.

27. Purohit BM, Singh A, Acharya S, Bhat M, Priya H. Assessment and validation of the oral impact on daily performance (OIDP) instrument among adults in Karnataka, South India. Community Dental Health 2012; 29: 203-208.

28. Pereira KC, Lacerda JT, Traebert J. The oral impact on daily performances and self-reported quality of life in elderly people in Florianopolis, Brazil. Oral Health Prev Dent 2009; 7: 163-172.

29. Gomes AS, Abegg C, Fachel JM. Relationship between oralclinical conditions and daily performances. Braz Oral Res 2009; 23: 76-81.

30. Lawal FB, Taiwo JO, Oke GA. Impact of oral health on the quality of life of elementary school teachers. Ethiop J Health Sci 2015; 25: 217-224.

31. Adekoya-Sofowora C, Nasir W, Oginni A et al. Dental caries in 12-year -old suburban Nigerian school children. African Health Sciences 2006; 6: 145-150.

32. Ilha L, Martins AB, Abegg C. Oral impact on daily performance: need and use of dental prostheses among Brazilian adults. J Oral Rehabilitation 2016; 43: 119-126. 


\section{APPENDIX - QUESTIONNAIRE}

SL. NO:

Date:

Place:

1. Name:

Age:

Sex:

2. Profession (Occupation):

\section{KUPPUSWAMY SCALE FOR THE ASSESSMENT OF SOCIO-ECONOMIC STATUS:}

Total Socioeconomic Class Score

26-29 Upper (I)

16-25 Upper middle (II)

11-15 Lower middle (III)

5-10 Upper lower (IV)

$<5$ Lower (V)

\section{(A) Education Score}

1. Profession or honours

2. Graduate or post graduate

3. Intermediate or post high school diploma

4. High school certificate

5. Middle school certificate

6 . Primary school certificate

7. Illiterate

Score
7
6

5
4
3
2
1

(B) Occupation Score

1. Profession

2. Semi-profession

3. Clerical, shop-owner, farmer

4. Skilled worker

5. Semi-skilled worker

6. Unskilled worker

7. Unemployed
Score

10

6

5

4

3

2

1

(C) Family income (Rs.) per month in the modified Kuppuswamy scale\#

1. $\geq 31,507$

2. $15,754-31,506$

3. $11,817-15,753$

4. $7,578-11,816$

5. $4,727-7,877$

6. $1,590-4,726$

7. $\leq 1,589$

12
10
6
4
3
2
1

3. The oral impact on daily performance

Have you experienced any difficulty in daily performance caused by problems with mouth, teeth or dentures in the past 6 month? Please tick the frequency that this happens.

\begin{tabular}{l|l|l|l|l|l}
\hline Performance & $\begin{array}{l}\text { Never } \\
\text { affected } \\
\text { in past } \\
6 \text { months }\end{array}$ & $\begin{array}{l}\text { Less than } \\
\text { once } \\
\text { a month }\end{array}$ & $\begin{array}{l}\text { Once or } \\
\text { twice a } \\
\text { month }\end{array}$ & $\begin{array}{l}\text { Once or } \\
\text { twice } \\
\text { a week }\end{array}$ & $\begin{array}{l}\text { Every or } \\
\text { nearly } \\
\text { every day }\end{array}$ \\
\hline Eating and enjoying food & & & & \\
\hline Speaking and pronouncing clearly & & & & \\
\hline Cleaning teeth & & & & \\
\hline Sleeping and relaxing & & & & \\
\hline Smiling, laughing and showing teeth without embarrassment & & & & \\
\hline Maintain usual emotional state without being irritable & & & & \\
\hline Carrying out major work or social role & & & & \\
\hline Enjoying contact with people & & & & \\
\hline
\end{tabular}


To what extent is your oral health problem affecting your daily activities?

\begin{tabular}{l|l|l|l}
\hline Performance & Mild effect & Moderate effect & Severe effect \\
\hline Eating and enjoying food & & & \\
\hline Speaking and pronouncing clearly & & & \\
\hline Cleaning teeth & & & \\
\hline Sleeping and relaxing & & & \\
\hline Smiling, laughing and showing teeth without embarrassment & & & \\
\hline Maintain usual emotional state without being irritable & & & \\
\hline Carrying out major work or social role & & & \\
\hline Enjoying contact with people & & & \\
\hline
\end{tabular}

\section{DENTITION STATUS}

\begin{tabular}{|l|l|l|l|l|l|l|l|l|l|l|l|l|l|l|l|l|l|}
18 & 17 & 16 & 15 & 14 & 13 & 12 & 11 & 21 & 22 & 23 & 24 & 25 & 26 & 27 & 28 \\
\hline & & & & & & & & & & & & & & & \\
\hline & & & & & & & & & & & & & & & \\
\hline 48 & 47 & 46 & 45 & 44 & 43 & 42 & 41 & 31 & 32 & 33 & 34 & 35 & 36 & 38 & 37
\end{tabular}

DMFT $=$

\section{COMMUNITY PERIODONTAL INDEX}

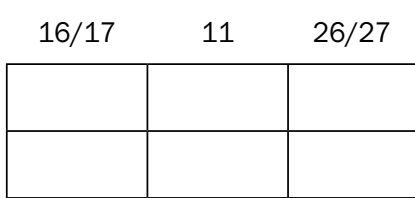

$47 / 46 \quad 31 \quad 36 / 37$

\section{LOSS OF ATTACHMENT}

\begin{tabular}{|l|l|l|}
\multicolumn{1}{|l}{$16 / 17$} & 11 & $26 / 27$ \\
\hline & & \\
\hline & & \\
\hline
\end{tabular}

$47 / 46 \quad 31 \quad 36 / 37$ 